\title{
NIETZSCHE COMO EDUCADOR: (el concepto de formación en el joven Nietzsche)
}

\author{
Juan David MATEU AlONSO* \\ Universitat de València
}

\begin{abstract}
RESUMEN: En las páginas que siguen quisiera presentar un breve análisis del concepto de formación (Bildung) en una de las obras de juventud de Friedrich Nietzsche: la tercera intempestiva, Schopenhauer como educador, texto poco analizado en la producción nietzscheana, pero que arroja luz sobre el proyecto general de la filosofía de juventud del filósofo alemán.

El esquema que seguiré es el siguiente: en un primer momento, trataré de mostrar la importancia del concepto de Bildung en la filosofía del joven Nietzsche, recurriendo especialmente a la segunda intempestiva (HL) ${ }^{1}$ y al ciclo de conferencias sobre el futuro de las instituciones de enseñanza (ZB). Ello servirá para ofrecer un somero marco dentro del cual, a continuación, me gustaría presentar los rasgos y trazos principales del concepto de formación en la tercera intempestiva (SE). Como punto final de este ensayo, me serviré de los vínculos entre Nietzsche y el ensayista americano R. W. Emerson para plantear las implicaciones y supuestos políticos del concepto de formación.
\end{abstract}

Palabras ClaVE: Nietzsche, Emerson, Formación (Bildung), instituciones de enseñanza,

* Este trabajo se ha realizado bajo el amparo de una Beca de Formación del Profesorado Universitario (FPU), AP-2004-1762, concedida por el Ministerio de Educación y Ciencia de España, y en el marco del grupo de investigación "Cultura y civilización" (Ministerio de Cultura, HUM200504665). He de agradecer a los profesores J. B. Llinares y V. Sanfélix, así como a mi compañero en el Dpto. de Metafísica y Teoría del conocimiento Bernat Martí, los comentarios críticos que plantearon a una versión previa de este texto.

1 Para el sistema de citas véase la bibliografía final. 


\section{La formación (Bildung) en la filosofía crítica del joven Nietzsche}

¿Cómo podríamos definir de manera provisional el concepto que nos ocupa? ¿Cómo justificar satisfactoriamente la versión castellana «formación» que hemos propuesto? En el diccionario Conceptos históricos fundamentales (Geschichtliche Grundbegriffe) encontramos que el concepto de Bildung atesoró a lo largo de su historia diversas connotaciones: desde imagen (Bild), imitación (Nachbildung), forma (Gestalt), hasta cualidad intelectual, comportamiento, o costumbre. También llegó a significar la capacidad imaginativa y sus representaciones. Sin embargo, en el periodo ilustrado se añadió de modo crucial y determinante el siguiente ámbito semántico: la educación, la cultura. Este último campo de significaciones es del que se ocupa primordialmente Nietzsche. ${ }^{2}$ La Bildung es un concepto un poco más genérico que la educación (Erziehung), en la medida en que recoge también aquellas otras significaciones (imagen, forma, conducta, imaginación); es una formación integral que se vincula también con un proyecto cultural comunitario, con una cultura (Kultur). Así pues, nuestra propuesta es verter el término Bildung por el castellano formación para poder recoger esa multiplicidad de significaciones, especialmente las primeras (educación, forma, conducta, imagen, imaginación), teniendo en cuenta el referente comunitario cultural que Nietzsche le quiere conferir al concepto vinculándolo con su filosofía crítica de la cultura.

Una vez presentada una primera aproximación general al concepto sería conveniente ocuparnos del marco general en el que se incardina el concepto de Bildung en la tercera intempestiva.

Podemos partir de la siguiente afirmación general: la filosofía del joven Nietzsche es una crítica de la cultura del presente a través del modelo que le ofrecen los antiguos griegos (intempestividad). El concepto de cultura se puede definir de

${ }^{2}$ Es significativo que el campo semántico del que se ocupa Nietzsche se forjara en la Ilustración. Cabría llevar a cabo un esbozo de comparación con el uso del concepto en obras como las de Kant, Hegel o incluso autores como Herder, Mendelssohn o Schiller. Para una breve historia del concepto se puede ver también H.-G. Gadamer, Verdad y método, Salamanca, Sígueme, 1977, pp. 38-48. De la misma manera su discípulo Koselleck ha incidido en que el concepto de Bildung es "el resultado de la Ilustración, y a la vez, una respuesta a ella» (Koselleck, 2002: 179). Así pues, una crítica de la Bildung, de la formación, sería una crítica interna al proyecto ilustrado, una crítica que comparte con lo criticado ciertos supuestos mínimos. 
dos modos; primero, por su constitución inherente: «Cultura es ante todo unidad del estilo artístico en todas las manifestaciones vitales de un pueblo» (DS, 163; HL, 274). Y, segundo, también por su finalidad: «...la producción del genio, esto es, la meta de toda cultura...) (SE, 358). En cierto modo, la filosofía social de Nietzsche, su concepto de persona y de formación, dependen de una determinada metafísica de la cultura, y del genio como fin de ésta.

Siguiendo con nuestro esbozo, el problema se desplaza, pues, a la formación, a la Bildung, que ha de producir el genio: la filosofía social y de la cultura está orientada por este fin, cuya condición de posibilidad es la libertad de las instituciones educativas respecto del Estado, reivindicación patente en SE y ZB. Además, la definición de educación (Erziehung) es para Nietzsche liberación (Befreiung) a la vez que consumación (Vollendung) de la naturaleza. Posteriormente volveremos sobre esta doble caracterización de la educación y la formación. No obstante, para ofrecer una primera definición del concepto de formación con sus criterios de uso, podemos recurrir a las conferencias de 1872 sobre el futuro de las instituciones de formación, previas a las consideraciones intempestivas. Allí se plantea una triple escala para medir la libertad y calidad de la formación: la necesidad de filosofia, el instinto por el arte y la consideración de la antigüedad greco-romana como el «imperativo categórico de toda cultura» (ZB, 741) ${ }^{3}$.

A continuación quisiera mostrar cómo este triple criterio (arte, filosofía y antigüedad) queda integrado en la segunda intempestiva dedicada justamente contra la «formación histórica» (historische Bildung). En primer lugar, según el propio Nietzsche, la formación histórica paraliza el impulso filosófico. Pero ¿̨cuál es pues la propuesta de Nietzsche?

«el origen de la formación histórica... a su vez, ha de ser conocido históricamente, la historia ha de resolver ella misma el problema de la historia, el saber ha de volver su aguijón contra sí mismo; esta triple obligación es el imperativo del espíritu de la "nueva era", si es que en ella hay realmente algo nuevo, potente, original y vitalizador» (HL, 306).

${ }^{3}$ Habrá que tener en consideración que en la época de Aurora (1881), el propio Nietzsche ensayará una autocrítica de este modelo de formación clásica (\$195), proceso de auto-reflexión que culminará en Crepuisculo de los ídolos, con "Lo que yo debo a los antiguos". 
En este texto encontramos de nuevo un triple imperativo, pero no ya respecto al concepto de formación, sino en relación con la "nueva era", esto es, la Modernidad. Si algo hay de valioso en ella, concede Nietzsche, es esa triple reflexividad (de la formación histórica, de la historia misma, y del saber en general). Dicha reflexividad es un claro indicio del papel de la filosofía como correctivo para el concepto de formación moderna. Es más, el triple criterio anterior para dicho concepto (arte, filosofía, antigüedad) se verifica a las claras en esta segunda intempestiva, pues tanto el arte como la filosofía son potencias suprahistóricas que permiten apreciar de modo crítico y suprahistórico aquello que supera los horizontes históricos, es decir, nos acercan a lo clásico ${ }^{4}$.

Justamente, además del arte y la filosofía, la antigüedad clásica es el principal correctivo para este concepto de formación histórica, cuyo pecado sería el de dividir al ser humano entre un interior cultivado y un exterior bárbaro, el de una formación enciclopédica que sólo sabría mirar hacia atrás sin apreciar lo que puede servir para la crítica y la construcción del presente hacia el futuro: habría que evitar que el espacio de experiencias redujera el horizonte de expectativas (Koselleck). Dicho con Nietzsche: "el sentido histórico, cuando opera sin freno y saca todas sus consecuencias, desarraiga el futuro" (HL, 295). De ello se sigue para Nietzsche que el sentido y la formación histórica han de corregirse de acuerdo con aquellos tres requisitos: la historia ha de dejar de ser ciencia para acercarse al arte (requisito estético), la filosofía ha de volver el aguijón del saber contra sí misma (requisito de reflexividad filosófica) y la imitación crítica ha de tener en cuenta la antigüedad, en la medida en que los antiguos griegos fueron capaces de «organizar el caos» de otras culturas (requisito clásico) ${ }^{5}$. Mediante esta refor-

4 "Los poderes ahistóricos se refieren al olvidar (Vergessen) y la ilusión (Wahn). Los suprahistóricos arte, religión, compasión, naturaleza, filosofía” (KSA, VII, 29 [194]).

${ }^{5}$ A propósito de la relación de los griegos con los pueblos de su entorno véase PhZG, 806 y HL, 333. «El imitar (Nachabmen) es el medio de toda cultura (Kultur), y al imitar se produce progresivamente el instinto. Todo comparar (pensar originario) es un imitar. Así se forman tipos, de modo que los primeros imitan reciamente sólo a ejemplares semejantes, esto es, copian al ejemplar mayor y más fuerte. La inculcación de una segunda naturaleza mediante imitación» (KSA, VII, 19 [226]). Este texto hace patente uno de los supuestos epistemológicos de Nietzsche: la imitación no es solamente un medio de desarrollo cultural inevitable y muy loable, sino que además tiene un carácter epistemológico muy acentuado en la medida que es el modo de pensar originario. Esto se relaciona con su lema epistémico, o más bien hermenéutico: lo igual se conoce por lo igual, tesis paralela a la de la conversión de la historia de ciencia en arte. Sólo haciendo uso de lo más elevado de uno mismo se puede encontrar lo equivalente en el otro (sea una cultura o un indivi 
ma se podría intentar una verdadera formación en una cultura digna de ser comparada con la antigüedad (la cultura trágica a la que aspira en El nacimiento de la tragedia), y cuyo fin último es la producción del genio, el ideal de persona.

Así pues, hemos visto brevemente que este triple requisito ya expuesto en 1872 en ZB, articula también la segunda intempestiva; mi propósito es en lo que sigue dedicarme a un análisis de la tercera intempestiva, donde el requisito de reflexividad filosófica es el protagonista, ya que allí es Schopenhauer, un filósofo, el que adopta el papel de educador, formador del verdadero genio.

\section{Formación y filosofía: Nietzsche como educador}

«...quien aquí habla no es, en el fondo, «Schopenhauer como educador", sino su antítesis, «Nietzsche como educador»" (EH, «Las intempestivas», $\$ 3)$.

"Nietzsche como educador»: este título que se presenta como la antítesis del título real de la tercera intempestiva es fruto de una reflexión en el último año de lucidez de Nietzsche, cuando ya hay una distancia insalvable con su maestro de juventud Schopenhauer. Sin embargo, en su juventud la antítesis no es tan explícita, sino que más bien lo que existe es una síntesis compleja, en la que Nietzsche asume y modifica las doctrinas del maestro en su propios términos. Pero esta síntesis de juventud nos permite ya hablar de "Nietzsche como educador», a partir de un ensayo que es un auténtico tratado de antropología filosófica, y esto en un doble sentido: no se trata sólo de una investigación filosófica sobre el ser humano, cuya principal tendencia a la pereza es criticada ya desde la primera línea del texto, sino también es filosófica, porque el ser humano necesita del filosofar para desarrollar su propio carácter, su genio. ¿Cómo conseguir este propósito? La contraposición entre individuo y masa marca la argumentación nietzscheana, que recurre asimismo a una reformulación de los versos de Píndaro: "Sé el que eres», "Sé tú mismo". Esta llamada a la autenticidad presu-

duo). Esto es lo que podríamos llamar el «supuesto de transferencia», o más bien la ley de asociación por semejanza, que también funciona en las metáforas, que para Nietzsche serían un objeto privilegiado de conocimiento, por delante del concepto, pues la metáfora consistiría en «tratar como igual lo que se ha reconocido en cierto aspecto como semejante» (KSA, VI, 19 [249]), mientras que "todo concepto se genera mediante la igualación de lo no-igual» (WL, 880). 
pone un grado de auto-conocimiento que sólo los dotados de una adecuada capacidad de reflexividad filosófica sobre la propia experiencia pueden asumir. El pindárico «sé tú mismo» presupone el socrático "conócete a ti mismo", tarea para la que Nietzsche se apoyará en el modelo de Schopenhauer. Pero no sólo Schopenhauer será el mentor filosófico de la formación por la que aboga Nietzsche; también el americano Ralph Waldo Emerson adquiere un papel crucial en la cuestión, pues en las primera páginas recoge ya Nietzsche un texto de su ensayo "Círculos», en el que se incide en que el ser humano se eleva justamente cuando desconoce la meta hacia la que camina ${ }^{6}$.

Para empezar con el análisis del concepto de formación, me ocuparé de una primera definición:

"...tus educadores no pueden ser sino tus liberadores. Y éste es el secreto de toda formación (Bildung): no proporciona prótesis artificiales, narices de cera, ni ojos de cristal. Lo que estos dones pueden dar es más bien la mera caricatura de la educación. Porque la educación no es sino liberación... ella es imitación y veneración de la naturaleza, en lo que ésta tiene de maternal y compasiva. Es, en fin, la consumación (Vollendung) de la naturaleza lo que lleva a plenitud su obra, previniendo sus golpes despiadados y crueles y haciéndolos mutar en bienes, cubriendo con un velo las expresiones de sus pensamientos de madrastra y su triste falta de comprensión" (SE, 341).

De este texto quisiera extraer algunas ideas que configuran el concepto de formación y nos servirán de hilo conductor en nuestra lectura.

En primer lugar, se habla de una ayuda externa, de unos educadores, de alguien que nos ha de prestar apoyo en la tarea de nuestra formación. En segundo lugar, esta tarea de formación es equiparada o cuando menos definida esencialmente como educación. En tercer lugar, la educación es liberación, imitación, veneración y consumación, y no compensación artificial mediante prótesis aña-

${ }^{6}$ Nietzsche cita en SE, 340 un texto que corresponde a la siguiente referencia de nuestra bibliografía: R. W. Emerson, 1983: 414. Nietzsche leyó a este autor en su temprana juventud, antes de leer a Schopenhauer, cuando todavía era alumno de Pforta, influyendo tremendamente en su formación como se puede apreciar en dos ensayos de juventud, "Destino e historia" y "Libre albedrío y destino". 
didas frente a la situación carencial del ser humano; pero ¿¿de qué libera, qué imita, venera y consuma esta educación?

La respuesta a esta cuestión es el cuarto punto: se produce una paradoja, porque todas esas acciones tienen el mismo referente, esto es, la naturaleza. Es de ella de quien nos hemos de liberar, a quien hemos de imitar y venerar, y también la que hemos de consumar con nuestra formación.

Esto podría producir cierta aporía conceptual, y ello es así también en la medida que Nietzsche incide en que la formación no es una prótesis «artificial» (kïnstliche Gliedmaa_en), sino algo que tiene que ver con la naturaleza. ¿Cómo presenta Nietzsche esta aporía conceptual? El procedimiento nietzscheano es el recurso a la doble metáfora de la madre y la madrastra naturaleza: esta metáfora maternal completa la personificación de la naturaleza iniciada con las acciones referidas a ella y que definen la formación. Podría decirse que la personificación maternal de la naturaleza es la condición de posibilidad de la formación de la persona y el genio en Nietzsche (su filosofía social depende de una filosofía de la naturaleza) ${ }^{7}$. A su vez, la doble metáfora maternal (esto es, considerar a la naturaleza como madre y madrastra) es la condición de posibilidad del concepto de formación (recordemos que en WL el concepto es el residuo de una metáfora). Así pues, el concepto de formación dependería no sólo de una concreta metafísica de la naturaleza, sino más bien de una «metaforología» de la naturaleza.

Si recuperamos el título de la intempestiva, hemos de reflexionar sobre el papel de Schopenhauer: es el modelo a seguir para Nietzsche, justamente porque vivió

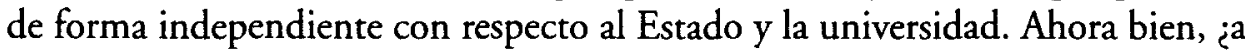
qué se opone este concepto de formación como liberación, imitación, veneración y consumación de la doble naturaleza? Justamente a una formación dirigida por el Estado moderno, a la sumisión a los mandatos políticos. Aquí está en juego la

\footnotetext{
${ }^{7}$ Una investigación sobre la filosofía de la naturaleza del joven Nietzsche requeriría un esfuerzo que no podemos dedicarle aquí. Sólo me limitaré a apuntar lo siguiente. Habría que advertir hasta qué punto son compatibles para Nietzsche el devenir de Heráclito y la lectura de Schopenhauer, una tensión que se advierte en PhZG, 825-826; asimismo habría que tener en cuenta la Critica del juicio de Kant, obra que Nietzsche leyó como estudiante en Leipzig. Evidentemente, una de las claves es el concepto de «agon»: la naturaleza, así como la sociedad griega, se caracterizarían por este aspecto agónico. Así lo reconoce el propio Deleuze cuando incide en el par de fuerzas activas-reactivas en su interpretación de Nietzsche.
} 
oposición del Estado moderno a una cultura verdadera orientada hacia la creación del genio, una cultura verdadera que es definida en relación a la naturaleza: la cultura es «naturaleza transfigurada» (SE, 362), «una Physis nueva y mejorada» (HL, 334). De nuevo la naturaleza es el punto de referencia, no sólo ya para la formación (Bildung), sino también para la cultura (Kultur). De hecho, en la oposición entre Estado moderno y cultura se emplea la siguiente metáfora botánica: el dominio del Estado moderno supone «la total exterminación y el desarraigo de la culturan (SE, 366). En esta oposición se plantean tres posibles imágenes del ser humano, de la persona, cuyos paradigmas serían Rousseau, Goethe y Schopenhauer: los dos primeros modelos son descartados por Nietzsche pues conllevan diversos peligros. El primero idealiza la naturaleza en exceso y se desprecia a sí mismo, con la consecuencia de convertirse en un revolucionario. El segundo es excesivamente conservador y conciliador, corriendo el peligro de devenir un filisteo de la cultura. La alternativa es clara: Schopenhauer es el modelo a seguir, pues es capaz de soportar el sufrimiento de la veracidad, que en definitiva no es otro que el causado por la sabiduría trágica, la verdad del Sileno sobre la efímera existencia humana. Precisamente, los modelos de hombres veraces, del tipo schopenhaueriano del genio, son el filósofo, el artista y el santo, porque ellos son capaces de soportar esa sabiduría trágica. Son el objetivo de la cultura auténtica en tanto que naturaleza completa y perfeccionada: «Se trata de la idea fundamental de la cultura (Kultur), en la medida que nos impone a cada uno de nosotros una única tarea: alentar el surgimiento del filosofo, del artista y del santo en nosotros y fuera de nosotros, trabajando asi a un tiempo en el perfeccionamiento y la consumación (Vollendung) de la naturaleza» (SE, 382). Esta teleología de la cultura como naturaleza mejorada orientada a la formación (Bildung) del genio indica ya el fin supremo de la filosofía del joven Nietzsche: la creación de grandes individuos por encima de la mediocridad de la masa, pues justamente en ellos se lograría la propia autoconciencia de la naturaleza. La madre naturaleza sería consciente de sí en sus creaciones supremas, que le servirían de espejo en el que se refleja su propia personalidad. En este punto comenzamos a toparnos con las ideas más arriesgadas y quizá peligrosas de Nietzsche: se trata de su tesis de la orientación e incluso sacrificio vital de la masa a favor del genio. Si bien podemos aceptar su crítica del utilitarismo, no parece aportar razones convincentes en defensa de su individualismo radical, e incluso podría ser contraproducente en la medida en que una de sus tesis es la siguiente: «Es preciso implantar y cultivar en la persona joven la idea de que ella misma tiene que considerarse como una obra fracasada de la naturaleza. $\mathrm{Y}$, a la vez, como una prueba viva de los designios e intenciones mayores y más 
admirables de esa artista» (SE, 385). Esta dualidad en la consideración de la persona humana, como obra fracasada a la vez que como prueba de lo admirable de la artista-naturaleza, atraviesa la filosofía social y la antropología del joven Nietzsche, dando pie a una tensión inherente que se puede traslucir en el campo de la política o de la propia filosofía de la cultura.

A propósito del concepto de cultura, SE nos ofrece una nueva definición que se añade a la que formulamos al inicio de este texto; ahora la cultura (Kultur) es "la hija del autoconocimiento de cada uno y de la insatisfacción en sí» (SE, 385). Esta definición recoge la tensión de la que veníamos hablando: la insatisfacción de re-conocerse como algo fracasado respecto al ideal de la naturaleza (guía de la cultura y la formación), pero que puede aspirar a él. La propuesta nietzscheana para superar este vacío entre autoconocimiento e insatisfacción es lo que él llama la consagración de la cultura, es decir, el reconocimiento del genio como el fin por el que se tiene que luchar. Sin embargo, como en tantas otras cuestiones referidas a Nietzsche, su propia posición se define más claramente si apreciamos los perfiles de los rivales a los que se enfrenta. El perfil común es el egoísmo, un egoísmo que sería propio de los siguientes grupos: los acomodados burgueses, la burocracia del Estado moderno, los carentes de capacidad estética, y la ciencia.

La oposición entre los científicos y el pensador que es propia del concepto nietzscheano de cultura daría lugar a una interesante contraposición en la que no puedo detenerme ahora. Sin embargo, sólo quisiera llamar la atención sobre un punto: la carencia de sensibilidad filosófica y artística que aparecía en el triple criterio de la formación mencionado anteriormente a propósito de $\mathrm{ZB}$, está de nuevo aquí presente. Pero ahora este criterio es completado con una crítica del Estado moderno y su interés de dirigir la formación (Bildung) hacia la conservación de las propias instituciones, y con una interesante crítica a la burguesía alemana del momento, una burguesía que había ya retratado como los "cultifilisteos" contra los que se dirige la primera intempestiva. Éste último punto es de gran interés porque aquí se pone de manifiesto el concepto de «formación rápida" (rasche Bildung) contra el que se opone la propuesta de Nietzsche:

«Sus adeptos definirían la formación (Bildung) como la capacidad de poner totalmente al día las necesidades y su satisfacción, haciéndose a la vez con todos los medios necesarios para ganar la mayor cantidad de dinero posible» (SE, 387). 
Huelga señalar el éxito de esta concepción economicista de la formación, y la necesidad de someterla a crítica. ¿Cómo es posible esta revisión crítica de la formación y de la educación? Desde una crítica filosófica independiente. De este modo, la tercera intempestiva concluye con una defensa de la libertad y la independencia de la filosofía respecto al Estado, independencia que lleva a Nietzsche a reivindicar la salida de la filosofía de la universidad para convertirse ella misma en el tribunal de ésta. En este contexto aparece de nuevo la figura de Ralph W. Emerson, el filósofo americano, que para Nietzsche es un modelo a seguir en cuanto a la radicalidad crítica de la filosofía, pues ésa y no otra es su función: molestar, conturbar, importunar, afligir (betrüben) como la filosofía de Diógenes el cínico ${ }^{8}$. Pero ¿por qué la intempestiva dedicada a Schopenhauer arranca y concluye con referencias a Emerson? A esta cuestión dedicaré la conclusión de esta comunicación.

\section{Perfeccionismo moral y democracia}

Stanley Cavell y George J. Stack han llamado la atención sobre los paralelismos, afinidades e influencias entre Emerson y Nietzsche: aquí sólo me referiré a un punto muy concreto, el que concierne al concepto de formación y de persona. La tesis central es la siguiente: tanto Emerson como Nietzsche defenderían un perfeccionismo moral, es decir, una teoría según la cual el propósito de las instituciones es la maximización de la excelencia individual. Por ejemplo, Rawls considera peligrosa esta idea para su teoría de la justicia y considera que una versión fuerte del perfeccionismo, que atribuye a Nietzsche, es incompatible con la democracia. La respuesta de Cavell a Rawls es que si esto es así, también Emerson ha de ser tenido como antidemócrata, lo cual sería insostenible, defendiendo por tanto que en Nietzsche habría un compromiso democrático, y que es posible que haya un perfeccionismo que no sea antidemocrático ${ }^{9}$. No voy a entrar a

${ }^{8}$ Precisamente a propósito de la tercera intempestiva ofrece Gilles Deleuze la siguiente reflexión sobre la tarea de la filosofía: "Cuando alguien pregunta para qué sirve la filosofía, la respuesta debe ser agresiva ya que la pregunta se tiene por irónica y mordaz. [...] La filosofía sirve para entristecer. Una filosofía que no entristece o no contraría a nadie no es una filosofía. Sirve para detestar la estupidez, hace de la estupidez una cosa vergonzosa. Sólo tiene este uso: denunciar la bajeza del pensamiento bajo todas sus formas" (Deleuze, 1986: 149).

9 "El particular desdén por la cultura oficial asumido por Emerson y por Nietzsche es él mismo una expresión de democracia y de compromiso con ella. [...] Sólo dentro de la posibilidad de la democracia se compromete uno a vivir con, o contra, tal culturan (Cavell, 1990: 50). 
debatir la compleja cuestión de la filosofía política de Nietzsche ${ }^{10}$, sino tan sólo apuntar algunas ideas que me servirán a modo de conclusión.

En primer lugar, tanto Emerson como Nietzsche pretenden una transformación de la humanidad, un cambio radical en la concepción del ser humano mediante un nuevo concepto de cultura y de formación, pero pese a las afinidades en la filosofia crítica de la cultura de ambos autores hay un importante matiz en su concepto de formación (Bildung - Upbuilding): mientras Emerson habla de revolución, Nietzsche habla de evolución hacia el ideal del genio ${ }^{11}$.

En segundo término, Emerson y el joven Nietzsche desconfían de la política para llevar a cabo esta tarea, que encomiendan a la educación del género humano de acuerdo con una determinada imagen de la naturaleza, que la política no haría más que violentar. La metafísica de la naturaleza tendría un papel regulativo para criticar la educación estatal marcando la idea de cultura que ha de servir de antítesis al Estado moderno. Esto lo muestra este texto de Emerson, que perfectamente podría encontrarse en el ensayo de Nietzsche sobre Schopenhauer:

«Sería inhumano no tener fe en el poder de la educación, puesto que mejorar es la ley de la naturaleza y valoramos a los hombres en la medida en que demuestran una fuerza que les lleva adelante y los mejora. [...] Hagamos nuestra educación valiente y preventiva. La política es un remiendo y un pobre parche. [...] Algún día aprenderemos a sustituir la política por la educación. Lo que llamamos nuestras reformas radicales en materia de esclavitud, guerra, juego, insolencia, es sólo tratamiento de los síntomas. Hemos de empezar por lo más elevado, es decir, por la educación» (Emerson, 1983: $1019-1020)^{12}$.

${ }^{10}$ Para un estado de la cuestión, véase el libro de J. E. Esteban Enguita, así como el artículo de Hermann Siemens, ambos citados en la bibliografía.

${ }^{11}$ Cavell, 2004: 213. Véase por ejemplo, SE, 426, donde Nietzsche se refiere a Emerson. La cita de nuevo corresponde al ensayo "Circles", Emerson, 1983: 407-408. Allí se dice: "Beware when the great God lets loose a thinker on this planet. Then all things are at risk... A new degree of culture would instantly revolutionize the entire system of human pursuits». Esta es la idea central que quiere recoger Nietzsche en su ensayo: la capacidad de crítica de la filosofia y la posibilidad de crear una nueva idea de cultura para modificar los fines de la humanidad.

12 Este texto pertenece al capítulo "Culture" de The Conduct of Life, libro que Nietzsche leyó en su traducción alemana (Die Führung des Lebens). Esta traducción pertenece a la edición castellana (La conducta de la vida) de la editorial Pre-Textos, Valencia, 2004, ed. de J. Alcoriza y A. Lastra. 
Este punto reforzaría la idea de Cavell según la cual tanto Emerson como Nietzsche plantean una crítica interna al sistema democrático, desconfían de la política e inciden en la necesidad de una educación que profundice y corrija los excesos institucionales a favor de una auténtica cultura democrática. Sin embargo, aunque Cavell quiera suavizar la expresión de Nietzsche según la cual hemos de "vivir en provecho de los ejemplares más raros y valiosos» (SE, 384), y pretenda compatibilizar la filosofía nietzscheana con la democracia dándole una articulación kantiana (en términos del propio Cavell), tendría que hacer frente a la meta de la Bildung nietzscheana, esto es, la creación del genio, $\mathrm{y}$ asimismo tener en consideración que este fin orienta no sólo el concepto de formación, sino también la idea de Estado en el joven Nietzsche, un Estado que puede asumir la esclavitud y la explotación como un medio para conseguir dicho fin. Además, habría que tener en cuenta que Nietzsche no aboga por una formación generalizada, sino restringida, aristócrata, privilegiada, y enfrentada con toda aspiración demócrata protagonizada por el comunismo, que para Nietzsche compartiría con el liberalismo la concepción de la formación como algo rentable, como instrumento de acción material y económica ${ }^{13}$. Por ejemplo, G. J. Stack, siguiendo a Georg Brandes, uno de los primeros divulgadores de Nietzsche, califica de uradicalismo aristocrático" las posiciones tanto de Emerson como de Nietzsche.

Para concluir sólo quiero citar dos breves textos del prólogo titulado El Estado griego (invierno de 1872); el primero va referido a uno de los supuestos del concepto de formación para el joven Nietzsche, mientras que el segundo incide en la idea de persona y su dignidad:

«La formación (Bildung)... reposa sobre un fondo atroz... el hecho de que a la esencia de una cultura $(\mathrm{K} \mathrm{u} \mathrm{t} \mathrm{u} \mathrm{r})$ pertenece la esclavitud» $(\mathrm{FV}, 767)^{14}$.

13 "La formación general, es decir la barbarie, es justamente la condición previa para el comunismo. [...] De principio sólo se ve en la formación algo que trae provecho, de modo que pronto lo que trae provecho se confunde con la formación" (texto póstumo cit. en Janz, 2, 1981: 145). Este texto encuentra su paralelo en ZB 667-668, donde se incide en la influencia de los dogmas de la Nationalökonomie sobre la formación, y la idea de que ésta no puede tratar de solventar el "problema social», es decir, la situación de explotación laboral, más que al precio de convertirse en barbarie.

14 Ya en las conferencias ZB de comienzos de 1872 decía lo siguiente: "toda formación (Bildung) empieza con lo contrario de todo lo que ahora se alaba como libertad académica, con la obe- 
"...todo ser humano, con toda su actividad, no tiene dignidad (Würde) más que en la medida en que, consciente o inconscientemente, es instrumento del genio (Werkzeug des Genius)» (FV, 776).

Si bien se puede entender la crítica de Nietzsche como un intento de atacar el fondo atroz y oculto de la democracia del XIX, no menos cierto es que también es difícil hacer compatible ese supuesto de su concepto de formación (la esclavitud) y la consecuencia sobre la dignidad humana de dicho concepto (dignidad condicionada a la instrumentalidad en pro del genio), con una cierta idea de sociedad democrática por la que abogaría el propio Cavell. Sin embargo, esta discusión sobre la filosofía política permanecería abierta (véase el artículo de Siemens citado en la bibliografía), más allá del conflicto hermenéutico interno a la obra nietzscheana.

Así pues, he intentado mostrar los supuestos y la configuración del concepto de formación en el joven Nietzsche, para luego apuntar someramente las implicaciones de esto para su idea de persona y en última instancia para su filosofía social o política. Con ello sólo he pretendido señalar en una dirección en la que cabría indagar más en futuras investigaciones debido a la riqueza del tema y la polémica que suscita esta cuestión.

\section{Bibliografía:}

Los textos de Nietzsche se refieren a la paginación de la KSA, y se utilizan como siglas los títulos originales; se han utilizado las siguientes traducciones al castellano, aunque se han hecho algunas ligeras modificaciones:

Cavell, Stanley: «Aversive Thinking. Emersonian Representations in Heidegger and Nietzschem. Conditions Handsome and Unhandsome. Chicago U. Press, Chicago, 1990.

\footnotetext{
diencia, con la subordinación, con la disciplina, con la servidumbre» $(\mathrm{ZB}, 750)$. Evidencias en este sentido se pueden recoger también de su época en Pforta. Rememorando su paso por dicha institución, Nietzsche dirá lo siguiente: «Una misma disciplina es la que confiere su destreza al militar y al sabio. [...] ¿Qué se aprende en una escuela severa? Se aprende a obedecer y a mandar” (cit. en Janz, 1, 1981: 112).
} 
—: «Nietzsche». Cities of Words. Pedagogical Letters on a Register of the Moral Life. Harvard U. Press, Cambridge (Massachusetts), 2004.

DeLEUZE, Gilles: Nietzsche y la filosofia. Anagrama, Barcelona,1986. Trad. de Carmen Artal.

EMERSON, Ralph Waldo: Essays and Lectures. Library of America, New York, 1983.

Esteban EnGUITA, José Emilio: El joven Nietzsche. Politica y tragedia. Biblioteca Nueva, Madrid, 2004.

JanZ, Curt Paul: Friedrich Nietzsche. 1. Infancia y juventud. Alianza, Madrid, 1981. Versión de Jacobo Muñoz.

—: Friedrich Nietzsche. 2. Los diez años de Basilea 1869/1879. Alianza, Madrid, 1981. Versión de Jacobo Muńoz.

KOSELlECK, Reinhart: «The Anthropological and Semantic Structure of "Bildung»». The Practice of Conceptual History: timing history, spacing concepts. Foreword by Hayden White. Stanford U. Press, Stanford (CA), 2002.

NiETZSCHE, Friedrich W.: Kritische Studienausgabe. 15 Bd. Walter de Gruyter, Berlin/New York, 1988 (KSA).

—: Sobre el porvenir de nuestras escuelas. Tusquets, Barcelona, 2000. Ed. de Carlos Manzano ( $Z B$ en citas).

-: «Sobre verdad y mentira en sentido extramoral». Antologia. Península, Barcelona, 2003. Ed. de J. Llinares y G. Meléndez (WL en citas).

—: Consideraciones intempestivas, 1. Alianza, Madrid, 2000. Ed. de A. Sánchez Pascual (DS en citas).

-: "De la utilidad y los inconvenientes de la historia para la vida». Antologia. Península, Barcelona, 2003. Ed. de J. Llinares y G. Meléndez (HL en citas).

-: Schopenhauer como educador. Biblioteca Nueva, Madrid, 2001. Ed. de Jacobo Muñoz (SE en citas).

—: La filosofia en la época trágica de los griegos. Valedmar, Madrid, 2003. Trad. Luis Fernando Moreno Claros (PhZG en citas).

—: Cinco prólogos para cinco libros no escritos. Arena, Madrid, 1999. Trad. de A. del Río Herrmann (FV en citas).

-: Ecce Homo. Cómo se llega a ser lo que se es. Alianza, Madrid, 1998. Ed. de A. Sánchez Pascual (EH en citas). 
Rodriguez GONZALEZ, Mariano: «El filósofo como educador (Comentarios desde la Tercera Intempestiva)». Actas del II Congreso de la Sociedad Académica de Filosofia. Servizo de Publicacións e Intercambio Científico de la USC, Santiago de Compostela, 2005. Formato digital [CD - PDF].

SIEMENS, Hermann: «Nietzsche's Political Philosophy: A Review of Recent Literature». Nietzsche-Studien, 30/2001: 510-526.

StaCK, George J.: Nietzsche and Emerson. An Elective Affinity. Ohio U. Press, Athens (Ohio), 1992.

VIERHAuS, Rudolf: «Bildung». En Brunner, O.; Conze, W.; y Koselleck, R.: Geschichtliche Grundbegriffe. Bd. 1. Klett Verlag, Stuttgart, 1972. 